\title{
ROTURA HEPÁTICA ESPONTÂNEA NA SÍNDROME HELLP
}

\author{
HELLP syndrome and spontaneous liver rupture
}

\author{
Alexandre Coutinho Teixeira de FREITAS, Gustavo SCHULZ, Rafael MORI, Julio Cezar Uili COELHO
}

ABCDDV/666

Freitas ACT, Schulz G, Mori R, Coelho JC. Rotura hepática espontânea na síndrome hellp. ABCD Arq Bras Cir Dig 2009;22(3):179-80

RESUMO - Introdução - A síndrome HELLP, condição com sinais de hemólise, elevação de enzimas hepáticas e baixa contagem de plaquetas, é situação obstétrica que pode apresentar severas complicações para a mãe, incluindo hematoma subcapsular com risco de ruptura para a cavidade peritoneal. Relato do caso - Um caso de ruptura espontânea do fígado secundária a síndrome HELLP é apresentado. A paciente foi submetida à laparotomia exploradora devido a choque hemorrágico. Conclusão - A síndrome HELLP é condição patológica perigosa com risco de morte materno-fetal. Tratamento cirúrgico deve ser indicado quando existe associação à ruptura hepática.

DESCRITORES - Síndrome HELLP. Fígado. Complicações na gravidez.

\section{INTRODUÇÃO}

A síndrome HELLP, caracterizada por hemólise, elevação de enzimas hepáticas e plaquetopenia, é afecção obstétrica característica do terceiro trimestre que pode evoluir com complicações graves para mãe e para o feto, incluindo risco de óbito. Dentre essas complicações está a formação de hematoma hepático subcapsular com possibilidade de ruptura para a cavidade peritoneal.

O objetivo desta apresentação é relatar um caso de ruptura hepática espontânea em gestante submetida à laparotomia devido a quadro de abdome agudo hemorrágico.

\section{RELATO DO CASO}

Mulher de 26 anos, primigesta e previamente hígida iniciou quadro de hipertensão arterial na $38^{\mathrm{a}}$ semana de gestação manejada com alfametildopa. $\mathrm{Na} 42^{\mathrm{a}}$ semana teve dor abdominal em epigástrio e hipocôndrio direito, crise hipertensiva e entrou em trabalho de parto. Foi manejada com sulfato de magnésio com controle da pressão arterial. Os exames laboratoriais demonstraram elevação de transaminases, plaquetopenia e hemoglobina normal. Evoluiu com choque hipovolêmico e foi submetida à laparotomia e interrupção da gestação. Durante a operação foi encontrado hemoperitônio devido à uma laceração extensa do fígado

Trabalho realizado no Serviço de Cirurgia do Aparelho Digestivo do Hospital de Clínicas da Universidade Federal do Paraná (HC-UFPR), Curitiba, PR, Brasil.

Endereço para correspondência: Alexandre Coutinho Teixeira de Freitas, e-mail alexandrefreitas@ufpr.br com início na face diafragmática do lobo direito e extensão para face visceral e segmento II. Foi realizada manobra de Pringle, hepatorrafia, reposição volêmica e transfusão de concentrado de hemácias. Houve persistência do sangramento sendo optado pelo empacotamento hepático. Dois dias após foi reoperada sem evidência de hemorragia. Recebeu alta hospitalar após 11 dias de internação com prescrição de propranolol e alfametildopa.

\section{DISCUSSÃO}

A síndrome HELLP é uma variante da pré-eclâmpsia que ocorre em $0,2 \%$ a $0,6 \%$ das gestações ${ }^{2,4}$. Aparenta ser a manifestação final de um insulto desconhecido que determina diminuição dos níveis de prostaciclina e aumento dos de tromboxano. Isso leva à lesão endotelial microvascular, vasoespasmo, ativação e agregação plaquetária e deposição de fibrina ${ }^{3}$. Essa cascata de reações somente é encerrada após a interrupção da gestação.

Ocorre destruição eritrocitária e plaquetária nos pequenos vasos que apresentam lesão endotelial e depósitos de fibrina ${ }^{2}$. A elevação das enzimas hepáticas é originada da obstrução da perfusão hepática pelos depósitos de fibrina e agregados plaquetários nos sinusóides hepáticos ${ }^{2}$. Essa obstrução leva à necrose periportal, hemorragia intrahepática, hematoma subcapsular. A ruptura hepática ocorre em $2 \%$ dos casos, na maioria das vezes no período préparto $^{1,2}$. Em 1/3 dos casos ocorre durante o parto ou no período de até seis dias após ${ }^{1,2}$.

A laparotomia está indicada associada, se possível, à interrupção da gestação. Deve-se evitar a realização de 
hepatectomias regradas e segmentectomias ou a ressecção de áreas de necrose ou infarto e a remoção de hematomas intrahepáticos. É mais apropriado a mobilização hepática através da secção de seus ligamentos seguida pelo empacotamento com compressas ${ }^{4}$. Nos casos em que a hemorragia não é controlada por este método pode-se realizar ligadura da artéria hepática ${ }^{1,2}$. Uma alternativa no paciente com estabilidade hemodinâmica é a realização de arteriografia e embolização seletiva do ramo arterial sangrante. Na vigência de hemorragia incontrolável com as medidas convencionais pode-se realizar hepatectomia e realização de anastomose porto-cava. Esses pacientes devem ser submetidos a transplante hepático em no máximo 48 horas. Nos casos em que ocorre necrose hepática extensa e consequente insuficiência hepática progressiva, o transplante hepático também deve ser considerado ${ }^{2}$. Existem poucos relatos na literatura de transplante devido à síndrome HELLP. Uma revisão de 17 casos demonstrou mortalidade de $17 \%{ }^{2}$.

\section{CONCLUSÃo}

A síndrome HELLP é grave com consequências potencialmente letais para mãe e feto. A mortalidade materna é de $2 \%$ a $3 \%$. Entretanto, quando ocorrem adicionalmente complicações hepáticas, ela chega a $50 \%$. A mortalidade fetal varia de $10 \%$ a $60 \%$. O tratamento cirúrgico deve ser sempre pensado na vigência de quadro grave com ruptura hepática associada.

Freitas ACT, Schulz G, Mori R, Coelho JC. HELLP syndrome and spontaneous liver rupture. ABCD Arq Bras Cir Dig 2009;22(3):179-80

ABSTRACT - Background - HELLP syndrome, a condition with signs of hemolysis, elevated liver enzymes and low platelet count, is an obstetric condition that can present with severe complications to the mother including subcapsular hematoma with risk to peritoneal rupture. Case report - A case of spontaneous liver rupture secondary to HELLP syndrome is presented. The patient was submitted to exploratory laparotomy due to hemorrhagic shock. Conclusion - HELLP syndrome is a dangerous disease with death risk to mother and fetus. The surgical treatment can be indicated when there is an association to hepatic rupture.

HEADINGS - HELLP syndrome. Liver. Pregnancy complications.

\section{REFERÊNCIAS}

1. Reck T, Bussenius-Kammerer M, Ott R, Müller V, Beinder E, Hohenberger W. Surgical treatment of HELLP syndrome-associated liver rupture. An update. Eur J Obstet Gynecol Reprod Biol 2001; 99:57-65.

2. Shames BD, Fernandez LA, Sollinger HW, Chin LT, D'Alessandro AM, Knechtle SJ, Lucey MR, Hafez R, AI Musat, Kalayoglu M. Liver Transplantation for HELLP Syndrome. Liver Transplant 2005; 11:224-228.
3. Sibai BM. The HELLP syndrome (hemolysis, elevated liver enzymes, and low platelets): much ado about nothing? Am J Obstet Gynecol 1990;162:311-6.

4. Wolf JL. Liver disease in pregnancy. Med Clin North Am 1996;80:1167-87.

Fonte de financiamento: não há Conflito de interesse: não há Recebido para publicação: 08/12/2008 Aceito para publicação: 22/01/2009 